\title{
ON AN INCLUSION THEOREM
}

\section{HÜSEYIN BOR}

(Received 12 July 1999)

\begin{abstract}
We have established a relation between $\theta-\left|R, p_{n}\right|_{k}$ and $\theta-\left|R, q_{n}\right|_{k}$ summability methods, $k>1$, which generalizes a result of Sunouchi (1949) on $\left|R, p_{n}\right|$ and $\left|R, q_{n}\right|$ summability methods.
\end{abstract}

Keywords and phrases. Absolute summability, inclusion theorem, infinite series.

2000 Mathematics Subject Classification. Primary 40F05, 40G99.

1. Introduction. Let $\left(\theta_{n}\right)$ be a sequence of positive numbers and let $\sum a_{n}$ be a given infinite series with the sequence of partial sums $\left(s_{n}\right)$. We say that the series $\sum a_{n}$ is summable $\theta-|C, 0|_{k}, k \geq 1$, if

$$
\sum_{n=1}^{\infty} \theta_{n}^{k-1}\left|a_{n}\right|^{k}<\infty .
$$

If we take $\theta_{n}=n$, then $\theta-|C, 0|_{k}$ summability is the same as $|C, 0|_{k}$ summability. Let $\left(p_{n}\right)$ be a sequence of positive numbers such that

$$
P_{n}=\sum_{v=0}^{n} p_{v} \longrightarrow \infty \quad \text { as } n \longrightarrow \infty,\left(P_{-i}=p_{-i}=0, i \geq 1\right)
$$

The sequence-to-sequence transformation

$$
t_{n}=\frac{1}{P_{n}} \sum_{v=0}^{n} p_{v} s_{v}
$$

defines the sequence $\left(t_{n}\right)$ of the $\left(R, p_{n}\right)$ mean of the sequence $\left(s_{n}\right)$, generated by the sequence of coefficients $\left(p_{n}\right)$ (see [3]). We say that the series $\sum a_{n}$ is summable $\theta-\left|R, p_{n}\right|_{k}, k \geq 1$, if

$$
\sum_{n=1}^{\infty} \theta_{n}^{k-1}\left|t_{n}-t_{n-1}\right|^{k}<\infty
$$

In the special case when $\theta_{n}=n$ (respectively, $k=1$ ), $\theta-\left|R, p_{n}\right|_{k}$ summability is the same as $\left|R, p_{n}\right|_{k}$ (respectively, $\left.\left|R, p_{n}\right|\right)$ summability. The $\left(R, p_{n}\right)$ mean is said to be absolutely $k$ th power conservative if $|C, 0|_{k} \Rightarrow\left|R, p_{n}\right|_{k}$. We say that the $\left(R, p_{n}\right)$ mean is absolutely $k$ th power $\theta$-conservative if $\theta-|C, 0|_{k} \Rightarrow \theta-\left|R, p_{n}\right|_{k}$.

A summability method $P$ is said to be stronger than another summability method $Q$, if the summability of a series by the method $Q$ implies its summability by the method $P$. If, in addition, the method $P$ sums the series to the same sum as that obtained by $Q$, the method $P$ is said to include the method $Q$. The following theorem is known. 
THEOREM 1.1 (see [4]). Suppose that $p_{n}>0, P_{n} \rightarrow \infty$ and suppose similarly that $q_{n}>0, Q_{n} \rightarrow \infty$. In order that

$$
\left|R, p_{n}\right| \Longrightarrow\left|R, q_{n}\right|
$$

it is sufficient that

$$
\frac{q_{n} P_{n}}{p_{n} Q_{n}}=O(1)
$$

In 1950, while reviewing [4], Bosanquet [2], observed that (1.6) is also necessary for the conclusion and completed Theorem 1.1 in necessary and sufficient form.

2. The main result. The aim of this paper is to generalize Bosanquet's result for $\theta-\left|R, p_{n}\right|_{k}$ and $\theta-\left|R, q_{n}\right|_{k}$ summability, where $k \geq 1$. Now, we shall prove the following theorem.

THEOREM 2.1. Let $k>1$. In order that

$$
\theta-\left|R, p_{n}\right|_{k} \Rightarrow \theta-\left|R, q_{n}\right|_{k}
$$

should hold (1.6) is necessary. If we suppose that $\left(R, q_{n}\right)$ is "absolutely kth power $\theta$-conservative," i.e.,

$$
\theta-|C, 0|_{k} \Longrightarrow \theta-\left|R, q_{n}\right|_{k}
$$

then (1.6) is also sufficient.

It should be noted that, if we take $k=1$ in this theorem, then we get Bosanquet's result. Also if we take $\theta_{n}=n$, then we get another result related to $\left|R, p_{n}\right|_{k}$ and $\left|R, q_{n}\right|_{k}$ summability methods.

We need the following lemma for the proof of our theorem.

LEMMA 2.2 (see [1]). Let $k \geq 1$ and let $A=\left(a_{n v}\right)$ be an infinite matrix. In order that $A \in\left(l^{k}, l^{k}\right)$ it is necessary that

$$
a_{n v}=O(1) \quad(\text { all } n, v) .
$$

\section{Proof of the theorem}

NeCESSITY. For the proof of the necessity, we consider the series-to-series version of (1.3), i.e., for $n \geq 1$, let

$$
\begin{gathered}
b_{n}=\frac{p_{n}}{P_{n} P_{n-1}} \sum_{v=1}^{n} P_{v-1} a_{v}, \\
c_{n}=\frac{q_{n}}{Q_{n} Q_{n-1}} \sum_{v=1}^{n} Q_{v-1} a_{v} .
\end{gathered}
$$

If we consider (3.1), we have

$$
P_{n-1} a_{n}=\frac{P_{n} P_{n-1}}{p_{n}} b_{n}-\frac{P_{n-1} P_{n-2}}{p_{n-1}} b_{n-1} .
$$


Hence

$$
a_{n}=\frac{P_{n}}{p_{n}} b_{n}-\frac{P_{n-2}}{p_{n-1}} b_{n-1} .
$$

A simple calculation shows that for $n \geq 1$,

$$
c_{n}=\frac{q_{n}}{Q_{n} Q_{n-1}} \sum_{v=1}^{n-1} \frac{b_{v}}{p_{v}}\left(Q_{v-1} P_{v}-P_{v-1} Q_{v}\right)+\frac{q_{n} P_{n}}{p_{n} Q_{n}} b_{n} .
$$

From this we can write down at once the matrix $A$ that transforms $\left(\theta_{n}^{1-1 / k} b_{n}\right)$ into $\left(\theta_{n}^{1-1 / k} c_{n}\right)$. Thus every $\theta-\left|R, p_{n}\right|_{k}$ summable series $\theta-\left|R, q_{n}\right|_{k}$ summable if and only if $A \in\left(l^{k}, l^{k}\right)$. By the lemma, it is necessary that the diagonal terms of $A$ must be bounded, which gives that (1.6) must hold.

SUFFICIENCY. Let $c_{n, 1}$ denote the sum on the right-hand side of (3.5) and let $c_{n, 2}$ denote the second term on the right-hand side of (3.5). Suppose the conditions are satisfied. Then it is enough to show that if

$$
\sum_{n=1}^{\infty} \theta_{n}^{k-1}\left|b_{n}\right|^{k}<\infty
$$

we have

$$
\sum_{n=1}^{\infty} \theta_{n}^{k-1}\left|c_{n, i}\right|^{k}<\infty \quad(i=1,2)
$$

For $i=2$ this is an immediate corollary of (1.6). Now consider $i=1$. We have

$$
Q_{v-1} P_{v}-P_{v-1} Q_{v}=-P_{v} q_{v}+p_{v} Q_{v}=O\left(p_{v} Q_{v}\right)
$$

by (1.6). Thus

$$
c_{n, 1}=O\left(\frac{q_{n}}{Q_{n} Q_{n-1}} \sum_{v=1}^{n-1} Q_{v}\left|b_{v}\right|\right) .
$$

Now the assumption (2.2) can be stated in the form that if $\sum b_{v} \in \theta-|C, 0|_{k}$ and if

$$
d_{n}=\frac{q_{n}}{Q_{n} Q_{n-1}} \sum_{v=1}^{n} Q_{v-1} b_{v},
$$

then

$$
\sum_{n=1}^{\infty} \theta_{n}^{k-1}\left|d_{n}\right|^{k}<\infty
$$

Now, define

$$
b_{v}^{\prime}= \begin{cases}0 & (v=1), \\ \left|b_{v-1}\right| & (v \geq 2) .\end{cases}
$$

If $\sum b_{n} \in \theta-|C, 0|_{k}$, then $\sum b_{n}^{\prime} \in \theta-|C, 0|_{k}$ so applying (2.2) with $b_{n}$ replaced by $b_{n}^{\prime}$ (and making an obvious change of variable in the sum defining $d_{n}^{\prime}$ below) we see that if

$$
d_{n}^{\prime}=\frac{q_{n}}{Q_{n} Q_{n-1}} \sum_{v=1}^{n} Q_{v}\left|b_{v}\right|
$$


then

$$
\sum_{n=1}^{\infty} \theta_{n}^{k-1}\left|d_{n}^{\prime}\right|^{k}<\infty .
$$

Hence (3.7) (with $i=1$ ) follows from (3.9). This completes the proof of the theorem.

\section{REFERENCES}

[1] H. Bor, On the relative strength of two absolute summability methods, Proc. Amer. Math. Soc. 113 (1991), no. 4, 1009-1012. MR 92c:40006. Zbl 743.40007.

[2] L. S. Bosanquet, Math. Reviews 11 (1950), 654.

[3] G. H. Hardy, Divergent Series, Oxford University Press, 1949. MR 11:25a. Zbl 032.05801.

[4] G. Sunouchi, Notes on Fourier analysis. XVIII. Absolute summability of series with constant terms, Tôhoku Math. J. (2) 1 (1949), 57-65. MR 11:654b. Zbl 041.39101.

HÜSEYIN BOR: DEPARTMENT OF MATHEMATICS, ERCIYES UNIVERSITY, 38039 KAYSERI, TURKEY

E-mail address: bor@erciyes.edu.tr 


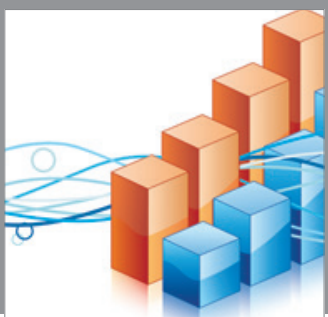

Advances in

Operations Research

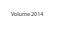

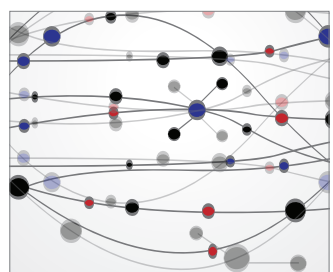

\section{The Scientific} World Journal
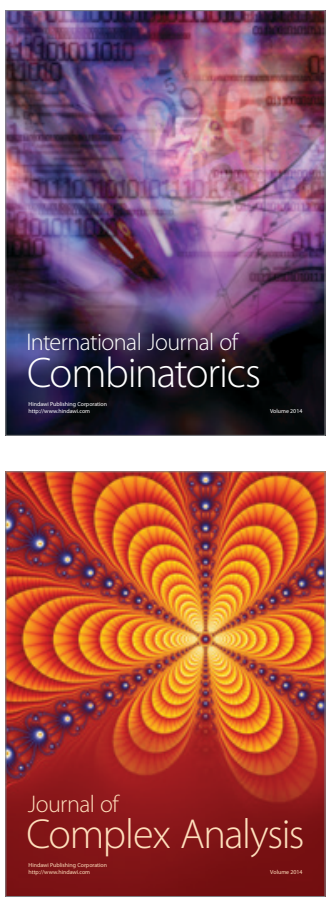

International Journal of

Mathematics and

Mathematical

Sciences
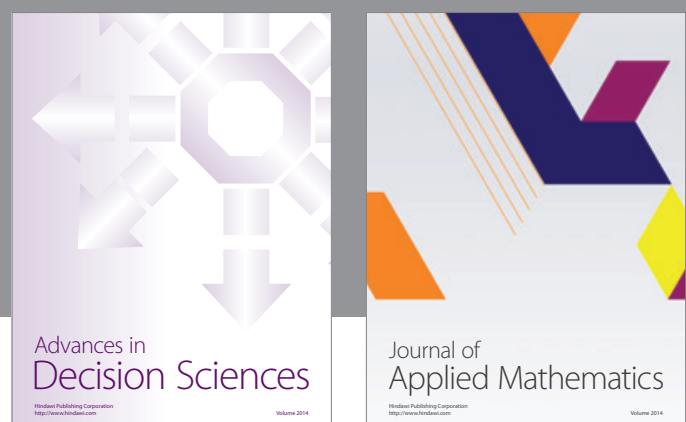

Journal of

Applied Mathematics
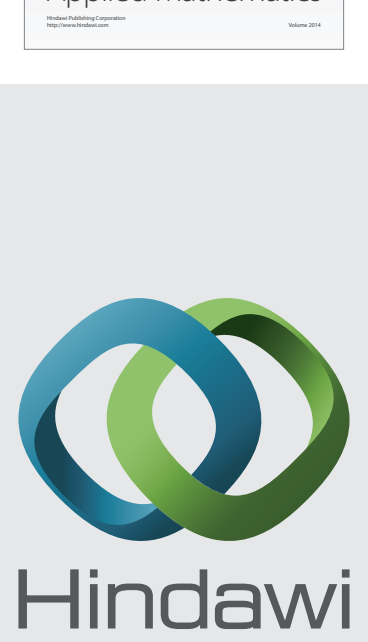

Submit your manuscripts at http://www.hindawi.com
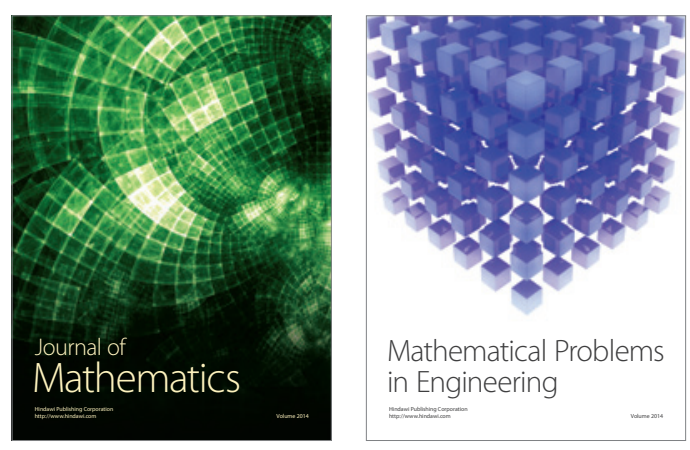

Mathematical Problems in Engineering
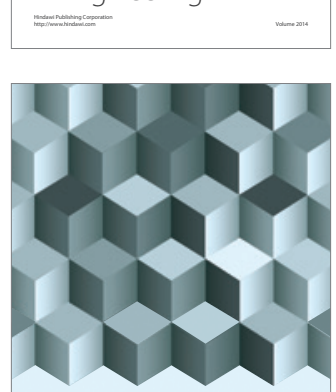

Journal of

Function Spaces
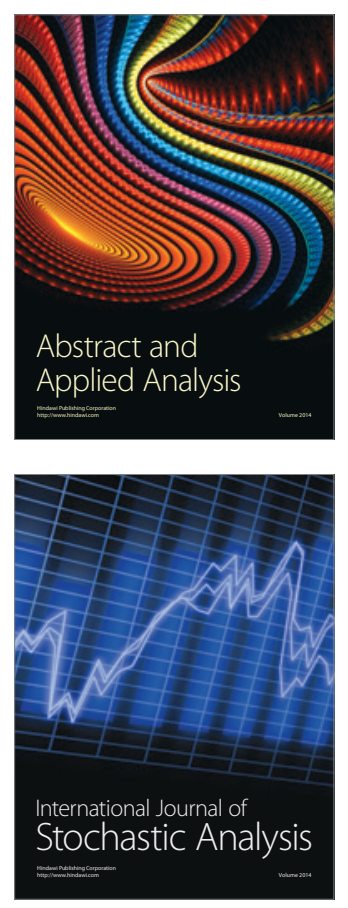

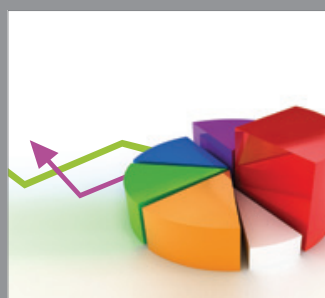

ournal of

Probability and Statistics

Promensencen
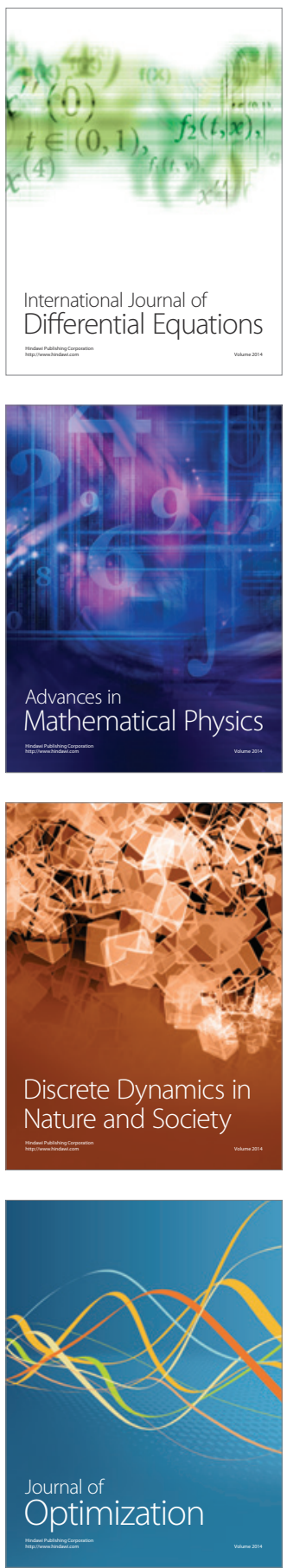